\title{
Long Term Intrathecal Baclofen Therapy in Patients with Intractable Spasticity
}

\author{
W.J. Becker, C.J. Harris, M.L. Long, D.P. Ablett, G.M. Klein and D.A. DeForge
}

\begin{abstract}
Background: Severe spasticity unresponsive to oral drugs may respond satisfactorily to baclofen delivered intrathecally. Methods: Intrathecal baclofen (IB) therapy delivered by means of implanted infusion pumps was used for nine patients with severe spasticity. Six patients had multiple sclerosis, two cervical spinal cord injury, and one head injury. All were non-ambulatory. Results: Patients showed improvement in many areas, including ability to transfer, seating, pain control, personal care, and liability to skin breakdown. Before IB therapy, only three of the nine patients were able to live at home in the community and six were institutionalized. At the end of our follow-up period, only one patient remained institutionalized, three lived in group homes and five lived at home in the community. In the year preceding pump implantation, the nine patients spent a total of 755 days in acute care hospitals. In the year following onset of IB therapy, they spent only 259 days in hospital. Conclusions: IB therapy can improve patient quality of life and can be cost-effective in carefully selected patients with severe spasticity and disability. The drug delivery catheter is that part of the therapeutic system most vulnerable to failure. Because of the varied expertise required to manage these patients effectively, and the potential for a variety of complications, it is essential that an IB program is supported by a well-organized multi-disciplinary medical team.
\end{abstract}

\begin{abstract}
RÉSUMÉ: Thérapie par le baclofen intrathécal chez les patients avec spasticité réfractaire au traitement. Introduction: La spacticité sévère réfractaire au traitement oral peut répondre de façon satisfaisante au baclofen intrathécal. Méthodes: Nous avons administré le baclofen par voie intrathécale (BI) au moyen d'une pompe implantée chez neuf patients avec spasticité sévère. Six patients avaient une sclérose en plaques, deux avaient un traumatisme de la moelle épinière cervicale et un avait subi un traumatisme crânien. Aucun d'eux ne marchait. Résultats: Nous avons observé une amélioration dans plusieurs domaines, dont la capacité de faire les transferts, la posture en position assise, le contrôle de la douleur, les soins personnels et la susceptibilité aux lésions cutanées. Avant le traitement, seulement trois des neuf patients étaient capables de vivre à domicile alors que les six autres étaient en institution. A la fin du suivi, seulement un patient demeurait en institution, trois demeuraient en foyer de groupe et cinq vivaient à domicile. Pendant l'année précédant l'implantation de la pompe, les neuf patients avaient au total séjourné dans un hôpital de soins aigus pendant 755 jours. Pendant l'année qui a suivi le début du traitement, ils ont passé seulement 259 jours à l'hôpital. Conclusions: La thérapie par BI peut améliorer la qualité de vie des patients et s'avérer économique chez un groupe de patients bien choisis, dont la spasticité et l'incapacité sont sévères. Le cathéter implanté est la partie du dispositif qui est la plus susceptible de faire défaut. Il est essentiel qu’un tel programme soit appuyé par une équipe médicale multidisciplinaire bien organisée parce que la prise en charge efficace de ces patients demande une expertise diversifiée et qu'une grande variété de complications peuvent survenir.
\end{abstract}

Can. J. Neurol. Sci. 1995; 22: 208-217

Intrathecal baclofen (IB) is a powerful and promising therapy for spasticity, ${ }^{1-13}$ but its expensive and invasive nature are potential barriers to its use. We report here our experience with IB therapy in a Canadian centre over a four year period. Given the cost of the implanted infusion pump, the potential complications associated with a surgically implanted system which includes a foreign body in the spinal fluid, and the need to maintain an infrastructure for regular pump refills and for treatment of complications, it is important that this therapy be carefully evaluated. Because of the costs involved, many medical centres and medical funding agencies are reluctant to embrace this therapy. We have therefore included a cost analysis of our treatment program. It is our experience that this very powerful therapy can have striking benefits for the patient, and can be very cost effective.
However, it is necessary to have a well organized program and careful patient selection to secure these benefits.

\section{METHODS}

The framework for our IB program was put in place in 1990 . The program was coordinated by a neurologist, who acted as the focal point for patient intake into the program, but who would consult widely with other team members. A second neurologist performed the blinded patient assessments during intrathecal

\footnotetext{
From the University of Calgary and the Calgary General Hospital, Calgary. RECEIVED JULY 22, 1994. ACCEPTED IN FINAL, FORM DECEMBER 5, 1994.

Reprint requests to: Dr. W.J. Becker, Calgary General Hospital, M6-012, 841 Centre Avenue E., Calgary, Alberta, Canada T2E 0A1.
} 
baclofen testing with the temporary spinal catheter. Other team members included the neurosurgeon who did the pump implantations and catheter revisions as necessary, the anesthetist who placed the temporary percutaneous spinal catheter for drug assessment, and did the bolus injections, the physiatrist who assisted in patient assessment for the program, and who followed the patients afterwards with regard to seating and other necessary rehabilitation measures, and the program nurse who supervised the pump refill program under the direction of the coordinating neurologist.

\section{Patient Selection}

Patients over the age of 18 years with severe disabling spasticity which was not responsive to oral medications and physical therapy were considered eligible for intrathecal baclofen therapy. Patients with significant psychiatric problems, or alcohol or drug abuse which might interfere their long term care in the program were excluded. In this report, we include all nine patients who had pumps implanted in our program prior to April 1993 and who therefore have one year follow-up or more. These included six patients with multiple sclerosis (MS), two patients with spinal injury, and one patient with head injury (Table 1). All patients were wheelchair bound, and many could not be properly seated because of their severe spasticity. Only three patients could transfer independently, although not necessarily safely, prior to IB therapy (patients S1, S2 and M4). Two patients, one with severe multiple sclerosis and one with head injury had significant dementia. At the time of implantation, six of the nine patients were institutionalized in either chronic or acute care hospitals, primarily because of their severe spasticity and the difficulties this caused in their management. Patient age, sex and disease duration are shown in Table 1.

The two spinal injured patients both had cervical spinal cord lesions secondary to trauma. Both had good arm function, and some preservation of sensation in the legs. S1 had no voluntary movement in the legs, whereas S2 did have some minimal preservation of motor function in the left foot. The single head injured patient had suffered post traumatic intracerebral hematomas, and showed residual diffuse cerebral atrophy. Prior to IB therapy, upper limbs were both severely flexed, the right leg was rigid and extended at the knee, but toes and feet werc plantar flexed. The six patients with multiple sclerosis were all severely disabled, with very little or no leg motor function, and with marked arm weakness. Only one of the multiple sclerosis patients (M1) showed significant dementia.

\section{Therapeutic Trials prior to Implantation}

Once a patient was selected for entry into the program, the patient was admitted to hospital, and a percutaneous spinal catheter inserted by the anesthetist. Daily bolus injections were then given intrathecally through this catheter, utilizing a bacterial filter, by the anesthetist. Injections consisted either of placebo, or varying baclofen dosages, ranging from 12.5 to 100 micrograms, with larger doses reserved for the latter portion of the therapeutic trial. The patient was assessed at hourly intervals before and after bolus injections by a neurologist blinded as to the nature of the injection. These assessments included Ashworth scores, muscle strength scores, bladder scores and spasm frequency scores. The temporary catheter could be left in place for as long as six days, and this was usually sufficient for testing to be completed. The majority of patients tested showed unequivocal dramatic relief of spasticity in response to intrathecal baclofen, as did all nine patients who proceeded to pump implantation. Several patients tested did not proceed to pump implantation. These included one patient in whom significant drug abuse became evident during her hospitalization, two patients with primarily intermittent spasms which were either not controlled adequately with the dosages used, or in whom on in-patient observation the symptoms did not appear to warrant intrathecal baclofen therapy, and one elderly man with primary lateral sclerosis in whom functional improvement was not considered adequate to warrant therapy despite relief of spasticity.

\section{Pump Implantation}

Pumps and catheters were implanted according to the manufacturers' instructions. Initially, non-programmable Infusaid ${ }^{a}$ pumps were used. Later in the program however, programmable

Table 1: Patients Implanted.

\begin{tabular}{|c|c|c|c|c|c|c|c|c|}
\hline Diagnosis & Patient & Age & Sex & $\begin{array}{c}\text { Disease } \\
\text { Duration }\end{array}$ & $\begin{array}{l}\text { Treatment } \\
\text { Duration } \\
\text { (months) }^{2}\end{array}$ & $\begin{array}{l}\text { Pump } \\
\text { Type }^{3}\end{array}$ & $\begin{array}{c}\text { Intrathecal B } \\
\text { Maximum } \\
\text { Daily Dose }\end{array}$ & $\begin{array}{c}\text { fen } \mu \mathrm{gm} / \mathrm{day} \\
\text { Current } \\
\text { Daily Dose }\end{array}$ \\
\hline & M1 & 34 & $\mathrm{M}$ & 11 years & 34 & I & 840 & 840 \\
\hline & M2 & 38 & $\mathbf{M}$ & 19 years & 28 & I & 445 & 445 \\
\hline Multiple & M3 & 56 & $\mathrm{~F}$ & 17 years & 25 & I & 480 & 480 \\
\hline \multirow[t]{3}{*}{ Sclerosis } & M4 & 42 & $\mathrm{~F}$ & 17 years & 23 & I & 810 & 780 \\
\hline & M5 & 35 & $\mathrm{~F}$ & 11 years & 13 & $\mathrm{M}$ & 150 & 135 \\
\hline & M6 & 42 & $\mathrm{~F}$ & 24 years & 13 & $\mathbf{M}$ & 570 & 570 \\
\hline Cervical & SI & 20 & $\mathrm{M}$ & 10 months & 47 & I & 160 & 160 \\
\hline Spinal Injury & $\mathrm{S} 2$ & 20 & $\mathrm{M}$ & 26 months & 19 & I & 330 & 330 \\
\hline Head Injury & $\mathrm{HI}$ & 20 & $\mathrm{M}$ & 27 months & 42 & I & 100 & 0 \\
\hline \multicolumn{9}{|c|}{$\begin{array}{l}\text { At intrathecal therapy onset } \\
2 \text { Intrathecal baclofen therapy - up to March, } 1994 \\
\quad \text { I = Infusaid (non-programmable) } \\
\text { M = Medtronic (programmable) }\end{array}$} \\
\hline
\end{tabular}

"Infusaid, Model No. 400, Infusaid Inc, 1400 Providence Highway, Norwood, MA 02062, USA

${ }^{b}$ Dual Access Synchromed Infusion System, Medtronic of Canada Inc, 6733 Kitimat Road, Mississauga, Ontario, Canada L5N I W3 
Medtronic ${ }^{b}$ pumps were used both because they offered more flexibility in terms of easily and rapidly changing dosages, and also because by using a concentrated baclofen solution in the reservoir and by utilizing a slow pump flow rate, the interval between pump refills could be greatly extended.

\section{Patient Assessment}

All patients were followed throughout their time in the program by the pump refill nurse. This allowed for continuous documentation of changes in patient status, such as level of pain, analgesic requirements, development of decubitus ulcers, change in residence, and hospitalizations. The clinical assessments of spasticity done during the patient's initial IB trial in hospital were available for later comparison. Activity of daily living assessments were done for some patients before and after IB therapy, as were assessments of leg spasticity using the KINCOM. ${ }^{c}$ A nursing assessment of each patient was done by the pump refill nurse using clearcut criteria such as a change in status from a two-man to a one-man transfer. This information was corroborated by the patient, and by medical personnel involved in the patient's care either from the institution involved where the patient was institutionalized, or by community health care workers. A patient satisfaction survey was also administered to all multiple sclerosis patients by the Multiple Sclerosis Clinic, focusing on a number of issues including ability to transfer, seating ability, personal hygiene, sleeping ability, mental functioning, pain control, spasticity control, and skin condition.

All complications occurring during IB treatment, including infections, the need for pump radio-contrast studies, surgical catheter revisions, pseudomeningocele repair, difficulty with pump refill, and respiratory distress were monitored by the study nurse and neurologist program coordinator.

\section{Pump Refill Procedures}

All pumps were refilled in our hospital out-patient department by our nurse coordinator, and one additional nurse who provided back-up during holidays, etc. Our nurse coordinator was trained by personnel from the pump manufacturers, and by the coordinating neurologist. The coordinating nurse was also the primary individual responsible for changing flow rates in Medtronic pumps using the computer programmer and telemetry wand. The coordinating nurse had immediate access as required to neurological, neurosurgical and rehabilitation backup.

\section{RESULTS}

\section{Baclofen Dosage}

In all nine patients, IB was able to reduce spasticity at doses which did not produce significant side effects. Maximum and current daily baclofen doses are shown in Table l, along with patient diagnosis and duration of therapy. In most patients, due to development of some drug tolerance, the current daily dose was also the maximum daily dose. Patient $\mathrm{Hl}$, our only patient with spasticity as a result of a head injury, was an exception. At 27 months after his head injury, this patient had such severe spasticity that he could not be seated adequately, and could not undergo appropriate physiotherapy. With the initiation of IB therapy, appropriate seating and physiotherapy was possible. He gradually began to improve, and eventually was able to walk with assistance. After four years of intrathecal therapy, the baclofen dosage was gradually tapered without diminishment in the patient's functional level, even though spasticity increased. Currently, the patient's pump is filled with saline, and he is undergoing observation prior to possible pump removal.

Significant drug tolerance was noted during IB therapy in most patients, leading to a gradual escalation of drug dosage. Patient drug dosages at 2, 6 and 12 months after initiation of therapy are shown in Table 2. As can be seen, drug dosages did escalate even after six months of therapy. Although in some patients with multiple sclerosis, progression of disease may have played a part in this escalation, drug tolerance likely is a significant factor. This was not usually a major limiting factor of therapy, as drug dosage could usually be increased sufficiently without major side effects. In two patients (S2, M3), dyspnea tended to occur as baclofen dosages were increased, and in two other patients (M2, M4), burning numbness in the lower body at times limited dosage increases, but adequate control of spasticity could still be maintained.

Table 2: Intrathecal Baclofen dosage ( $\mu \mathrm{gm} / \mathrm{day})$ during first 12 months of therapy.

\begin{tabular}{cccc}
\hline \multirow{2}{*}{ Patient } & \multicolumn{4}{c}{ Months After Initiation of Therapy } \\
& $\mathbf{2}$ & $\mathbf{6}$ & $\mathbf{1 2}$ \\
\hline M1 & 82 & 165 & 340 \\
M2 & 130 & 390 & 375 \\
M3 & 170 & 235 & 325 \\
M4 & 282 & 400 & 540 \\
M5 & 125 & 150 & 135 \\
M6 & 330 & 330 & 570 \\
S1 & 75 & 105 & 95 \\
S2 & 90 & 160 & 240 \\
H1 & 60 & 75 & 75 \\
\hline
\end{tabular}

\section{Control of Spasticity}

Spasticity could be relieved over the long term satisfactorily in most patients. In fact, in most patients care was taken not to abolish muscle tone completely, on the premise that complete flaccidity might predispose to venous thrombosis and that the ascending effects of high baclofen doses could result in weakness of remaining function in the upper limb and in respiration. The intermittent muscular spasms experienced by most of our patients were more difficult to control than the muscle tone per se, and it was not unusual for a patient to appear flaccid on examination, but to still complain about occasional intermittent spasms which were in some way troublesome. In these cases, an attempt was made to find a compromise dosage which would make the intermittent spasms tolerable but which not produce complete flaccidity or other side effects. This was at times difficult. In patient S1 who appeared very sensitive to the sedative properties of intrathecal baclofen, it was difficult to achieve a dosage which provided entirely satisfactory relief of intermittent spasms, and which at the same time did not cause sedation. At just over one year of therapy, patient M6 also complained of significantly troublesome muscle spasms at night at a time when clinical examination of her legs during the day showed complete

${ }^{c}$ Med-Ex Diagnostics of Canada Inc, 32 Voyager Court South, Rexdale, Ontario, Canada M9W 5M7 
flaccidity. This problem was resolved by programming the Medtronic pump to deliver a higher drug dosage at night than during the day. Patient Ml, although obtaining significant improvement in control of spasticity with consequent improvements in seating and nursing care, never did approach ideal control of spasticity. Initially a high enough drug dosage simply could not be delivered to this patient because of the limitations imposed by the patient's fixed flow rate Infusaid pump, and the concentration of intrathecal baclofen available $(0.5 \mathrm{mg} / \mathrm{ml})$. When higher concentrations of baclofen $(2.0 \mathrm{mg} / \mathrm{ml})$ became available, his control of spasticity improved, but this patient with severe progressive multiple sclerosis with longstanding dementia, dysphagia and dysarthria developed an aspiration pneumonia which led to chronic pulmonary complications and during this prolonged illness control of spasticity remained less than optimal.

Figure 1 shows the marked reduction in spasticity which was accomplished in patient $\mathbf{S} I$ by intrathecal therapy as demonstrated by objective testing before and during IB treatment using the Kin-Com.

\section{Patient Outcomes}

Patient quality of life improved in many ways following the initiation of IB therapy. One of the most striking benefits of therapy was the ability to seat the patient properly in a wheelchair. In patient M6, this allowed discharge from hospital, as this patient simply could not be seated beforehand and was essentially bedridden. Function was also greatly improved in patients $\mathrm{M} 4$ and $\mathrm{H} 1$, who prior to intrathecal baclofen therapy had a greatly reduced ability to use a wheelchair because their legs could not be bent at the knee. Better seating also had great implications for skin care in many of the patients, resulting in dramatically fewer episodes of skin breakdown. In the case of patient M5, 1B therapy allowed discharge after a prolonged hospitalization which had resulted in large part from skin breakdown which had necessitated skin grafting.

An example of the changes which occurred in the ability of patients to manage activities of daily living is shown in Figure 2 for patient $S 1$, a patient who prior to therapy suffered from severe muscular spasms. This patient made gains in a number of areas as shown. Especially dramatic was the fact that this patient no longer required supervision for transfers, as this patient could transfer safely after initiation of IB therapy. He was also able to drive a motor vehicle independently and safely after treatment, and as a result could become a full time student.

Table 3 shows patient outcome for a number of features in all nine patients. Patient transfers were considered to show major improvement if a two man transfer became a one man transfer, or if an unsafe transfer became a safe transfer. Major improvement was considered to have occurred in pain control based upon the patient's comments, if these were also collaborated by dramatic reduction in analgesic consumption, in most cases to 0 . Major improvements were considered to occur in skin brakdown if skin breakdown ceased in patients with repeated prior episodes of skin breakdown. Most patients who did not show major improvement did so because problems like pain control or skin breakdown were not present before IB treatment (for example patient $\mathrm{H} 1$ ). As can be seen, virtually all patients showed major improvement in at least several categories. The one exception was patient Ml, who had severe multiple sclerosis, marked fixed flexion contractures, visual loss, dysphagia, dysarthria and significant dementia prior to pump implantation. The results of IB therapy would appear less satisfactory in patients with such severe underlying disease where the opportunities for functional improvement are limited.

The results of a patient satisfaction survey done by our Multiple Sclerosis Clinic on the six multiple sclerosis patients are shown in Table 4 . These basically confirm the nursing assessment. The satisfaction survey is somewhat less positive with regard to skin condition than the nursing assessment as the satisfaction survey was done eleven months earlier at a time when several patients had only recently been implanted and were still awaiting chair and seating adjustments. Worthy of note, mental function was considered to have improved significantly by many patients, primarily because they no longer needed high dose oral medication to control their spasticity. Likewise, better control of spasms and pain significantly enhanced sleeping ability.

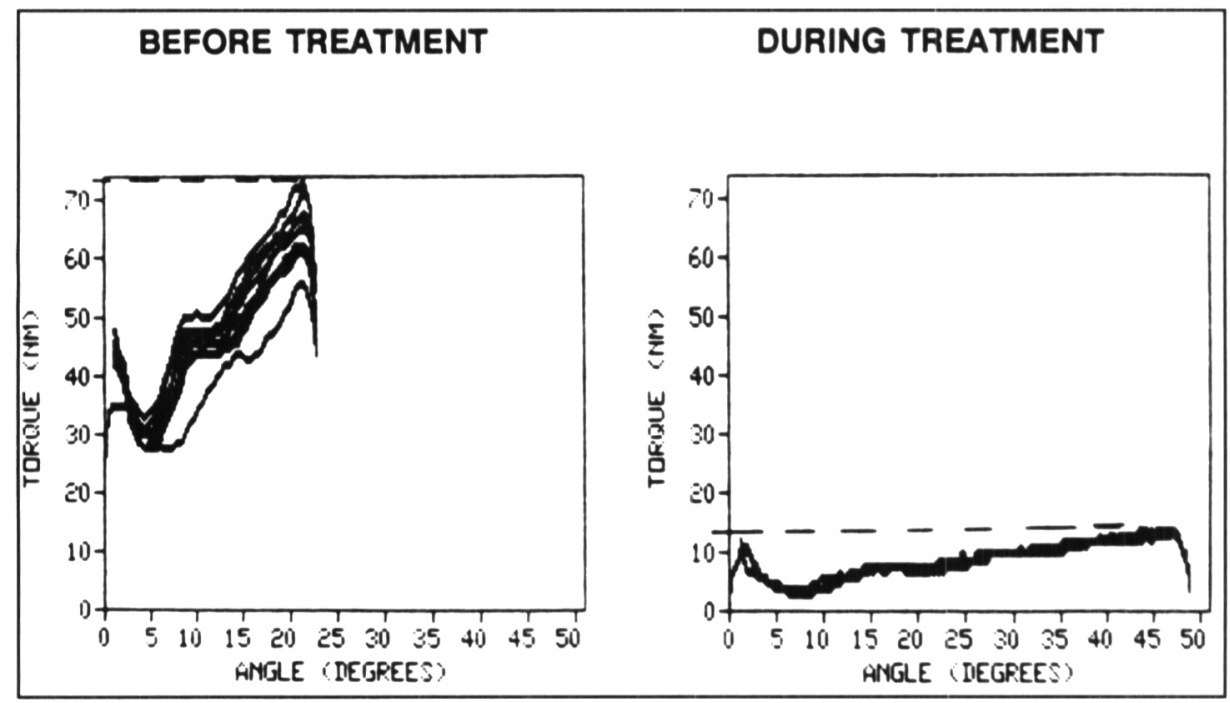

Figure 1: The torque required (in Newton-metres) to extend the knee joint in patient SI at a constant velocity (50\%sec) from $50^{\circ}$ flexion to $25^{\circ}$ flexion (by $K I N-C O M$ ) is shown before intrathecal baclofen treatment (left panel) and during intrathecal baclofen (right panel). Intrathecal baclofe'n greatly reduced the torque required to extend the leg, indicating a marked reduction in knee flexor muscle spasticity. 


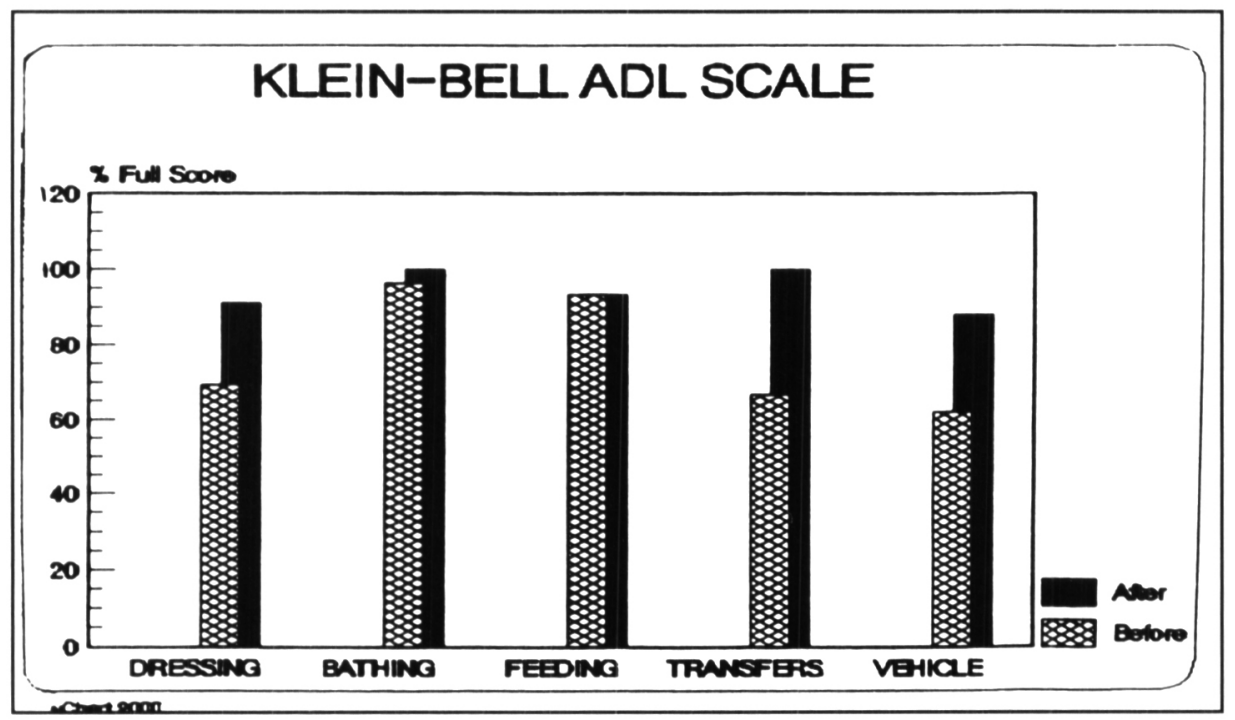

Figure 2: Klein-Bell activity of daily living scale scores for patient SI before and after intrathecal baclofen therapy was started. The following changes were noted with intrathecal baclofen therapy to account for the improvement in scores; dressing: can now reach shoes and socks; bathing/hygiene: can now clip toenails; transfers: no longer requires supervision; vehicle: can now drive safely and independently using mechanical lift.

Table 3: Patient Outcome - Nursing Assessment.

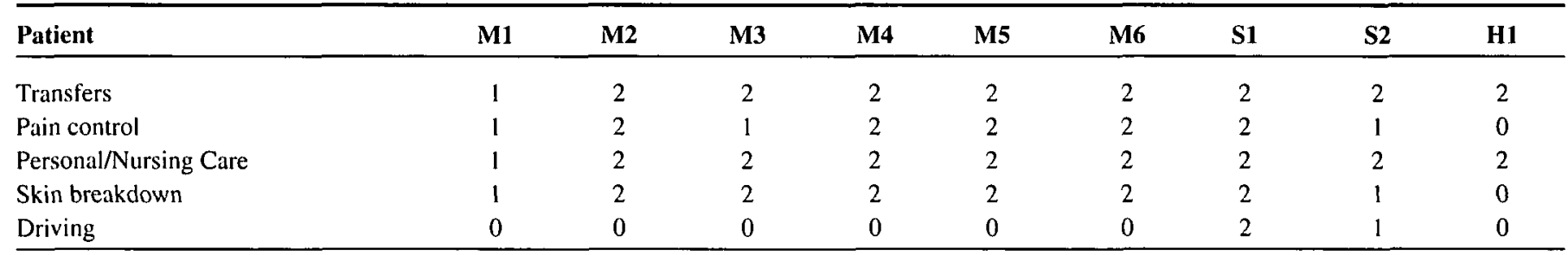

$\begin{array}{ll}\text { Rating Scale: } & 0=\text { no change } \\ & 1=\text { some improvement } \\ & 2=\text { major improvement }\end{array}$

Table 4: Patient Satisfaction Survey - Six Multiple Sclerosis Patients

\section{Pre-Pump Post-Pump}

Mean Patient Score Mean Patient Score

\begin{tabular}{lll}
\hline Ability to transfer & 1.1 & 4.6 \\
Seating ability & 1.6 & 4.6 \\
Personal hygiene & 1.8 & 4.6 \\
Sleeping ability & 1.6 & 4.5 \\
Mental functioning & 2.5 & 4.3 \\
Pain control & 1.3 & 4.0 \\
Spasticity control & 1.5 & 3.8 \\
Skin condition & 2.3 & 3.6 \\
\hline
\end{tabular}

Rating Scale: $\quad \mathrm{I}=$ very unsatisfied

$5=$ very satisfied

Mean scores for all six patients are shown pre-pump and post-pump.

\section{Cost Analysis}

Place of patient residence for our nine patients is shown in Table 5. As can be seen, IB therapy eventually allowed the discharge of three patients (M4, M5 and M6) after prolonged hospitalizations. Control of spasticity allowed discharge to the patient's home in two instances, and to a group home in the third instance. Prior to initiation of intrathecal baclofen therapy, there seemed little chance of discharge for these patients, except perhaps to a high level chronic care institution. Two additional patients, M2 and $\mathrm{H} 1$, could be discharged from chronic care institutions to group homes. In the case of M2 this was after many years of chronic institutionalization. Patient M1, with severe disability from multiple sclerosis, again demonstrated a relatively poor outcome, in that this patient could not be discharged from a chronic care institution because of his other disabilities, and eventually developed severe chest complications necessitating long term hospitalization.

Table 6 shows patient days in acute care hospitals for the one year period before IB therapy, as compared to the one year period after IB therapy. Hospital days related to IB testing using a temporary spinal catheter were credited to the post-intrathecal baclofen therapy year unless the patient was already hospitalized for therapy of severe spasticity or complications thereof. All hospitalizations relating to pump implantation were credited to the post-intrathecal baclofen year. As can be seen, total hospital days for the year prior to intrathecal therapy totalled 755 days, whereas in the year following initiation of therapy, hospital days for the nine patients totalled only 259. As shown in 
Table 5: Patient Residence.

\begin{tabular}{|c|c|c|c|c|c|c|c|c|c|}
\hline Patient & M1 & M2 & M3 & M4 & M5 & M6 & S1 & $\mathbf{S 2}$ & H1 \\
\hline Pre-Pump & I & I & $\mathrm{C}$ & $\mathrm{H}$ & $\mathrm{H}$ & $\mathrm{H}$ & $\mathrm{C}$ & $\mathrm{C}$ & 1 \\
\hline Post-Pump (one year) & I & I & $\mathrm{C}$ & $\mathrm{C}$ & $\mathrm{G}$ & $\mathrm{C}$ & C & $\mathrm{C}$ & I \\
\hline Post-Pump (current) & $\mathrm{H}$ & $\mathrm{G}$ & $\mathrm{C}$ & $\mathrm{C}$ & G & $\mathrm{C}$ & $\mathrm{C}$ & $\mathrm{C}$ & G \\
\hline $\begin{array}{l}H=\text { acute care hospital } \\
I=\text { chronic care institution } \\
\mathrm{G}=\text { group home } \\
\mathrm{C}=\text { in the community (at home) }\end{array}$ & & & & & & & & & \\
\hline
\end{tabular}

Table 6: Patient Hospitalizations - Before and After Intrathecal Baclofen (IB) Therapy.

\begin{tabular}{ccc}
\hline Patient & $\begin{array}{c}\text { Days in Hospital } \\
\text { Before IB } \\
\text { (one year period) }\end{array}$ & $\begin{array}{c}\text { Days in Hospital } \\
\text { After IB } \\
\text { (one year period) }\end{array}$ \\
\hline M1 & 12 & 23 \\
M2 & 0 & 24 \\
M3 & 60 & 39 \\
M4 & 120 & 48 \\
M5 & 139 & 21 \\
M6 & 319 & 10 \\
S1 & 42 & 33 \\
S2 & 1 & 31 \\
H1 & 62 & 30 \\
\hline Total: 9 Patients & $\mathbf{7 5 5}$ & $\mathbf{2 5 9}$ \\
\hline
\end{tabular}

Table 7: Patient Hospitalizations - Before and After Intrathecal Baclofen (IB) Therapy (at $\$ 570$ per hospital day).

\begin{tabular}{lccc}
\hline & $\begin{array}{c}\text { Hosptial Costs } \\
\text { Before IB } \\
\text { (one year period) }\end{array}$ & $\begin{array}{c}\text { Hospital Costs } \\
\text { After IB } \\
\text { (one year period) }\end{array}$ & Savings \\
\hline $\begin{array}{l}\text { patients } \\
\begin{array}{l}\text { Mean saving } \\
\text { per Patient }\end{array}\end{array}$ & $\$ 430,000$ & $\$ 148,000$ & $\$ 282,000$ \\
\hline
\end{tabular}

Table 7 , using $\$ 570$ as the cost of one hospital day, these figures indicated an average saving of over $\$ 31,000$ per patient in terms of reduction in hospital days in acute care hospitals alone. Our figures likely under estimate the real savings involved. Patients M1 and M2 had very few days in an acute care hospital in the year prior to IB therapy because both were already in a chronic care hospital, and days in chronic care institutions were not counted in our cost analysis. For patient SI, who had pump implantation within one year of his spinal cord injury, hospital days relating to the initial care of his spinal cord injury were not counted. The 42 days of pre-intrathecal baclofen therapy hospitalization considered in our cost analysis were hospital days which occurred after it was clearly documented on his chart that he could be discharged were it not for the presence of his intractable spasticity.

Balanced against this mean saving of $\$ 31,000$ per patient in the year following pump implantation, is the cost of the pump and related equipment (approximately $\$ 7,000$ per patient) and the cost of six to twenty-four refill procedures per patient, depending upon the type of pump and the flowrate used. Each refill procedure involves costs for disposable equipment (\$14.46), approximately $20-30$ minutes of nursing time $(\$ 13.50)$, and potential drug costs (intrathecal baclofen is currently supplied without charge in Canada as use of the drug remains experimental). Our current refill costs then are approximately $\$ 30$, not counting the use of out-patient space, etc. Any eventual intrathecal drug costs will be at least partly offset by the savings incurred because patients no longer require high dose oral spasticity therapy, and in many cases analgesia. Physicians costs in terms of managing these patients after implantation may well be less than those necessary to manage the patient's spasticity and complications thereof were IB therapy not initiated.

In summary, IB therapy in well-selected patients would appear to be markedly beneficial in terms of nursing assessment, patient satisfaction, and cost effectiveness.

\section{Complications}

Table 8 summarizes the complications seen. No patient required pump replacement, and meningitis and other infections potentially related to the pump or catheter did not occur. Four of our patients underwent a total of eight $\mathrm{x}$-ray contrast studies through injection of the pump sideport to evaluate catheter integrity. One "pump-o-gram" was therefore done for every 30.5 months of intrathecal baclofen therapy. Five of these eight studies were in fact done in patient $\mathrm{S} 1$, our first implanted patient and may reflect inexperience both in medical patient management and in the neurosurgical techniques. Of the eight pump-ograms, three were abnormal. Two showed catheter breakage or disruption, and the third showed retraction of the catheter from the intrathecal space. The other normal pump-o-grams were

Table 8: Complications - 9 Patients (Mean Duration of Therapy $=27$ months).

Total Number of Number of Patients

Complications Experiencing Complications

Pump replacement

Pump/Catheter infections

Meningitis

Pump radiocontrast studies

Surgical catheter revisions

Pseudomeningocele repair

Difficulty with pump refill

Pump ran dry

Respiratory distress

$\begin{array}{ll}0 & 0 \\ 0 & 0 \\ 0 & 0 \\ 8 & 4 \\ 4 & 2 \\ 2 & 2 \\ 5 & 1 \\ 2 & 4 \\ 2 & 2 \\ \end{array}$


done because of increasing spasticity, which in retrospect was likely due to drug tolerance, and further escalation of the intrathecal baclofen dosage satisfactorily resolved the problem in most instances.

Four surgical catheter revisions were done. Three of these occurred in our first patient, patient S1. Two revisions were done during the first two months of therapy in this patient, the first revision because the catheter was noted on plain $x$-ray to have withdrawn from the subarachnoid space, and the second because the catheter had a hole near the pump site. The third catheter revision for this patient was done over three years later, because the catheter had fractured. A catheter revision was also done in patient $\mathrm{M} 4$, in whom the catheter had retracted from the subarachnoid space. In total, two of our nine patients required catheter revisions with an average follow-up period of 27 months (a total of 244 patient-months of intrathecal baclofen therapy). With four surgical catheter revisions required over a total follow-up time of 244 months, statistically one of our patients could expect to require a catheter revision every 61 months, or approximately every five years. Excluding the first two months of therapy in our first patient, then only one catheter revision was required for every 121 months of therapy. With this calculation, a patient could expect to require a catheter revision approximately every ten years.

One patient, S2, noted a fluctuant swelling at the base of the spine shortly after pump implantation, and after an initial repair under local anesthesia was not successful, he underwent a successful second repair under general anesthesia.

During our follow-up period, which averaged 27 months per patient, our trained nursing staff was able to successfully perform the numerous pump refills required almost without incident. Only on five occasions did they require input from program physicians. In patient $\mathrm{S} 1$, on two occasions, the pump injection port could not be palpated because the patient's Infusaid pump had turned over in the pump punch, and the injection port therefore faced internally. In each instance, the neurosurgeon was able to easily flip the pump back to its original position by manual palpation through the abdominal wall without anesthesia, and the refill then proceeded uneventfully. In two patients, seromas of a significant size were present on the first post-implantation refill, which resulted in fluid aspiration from the abdominal wall prior to the pump being entered. Nursing staff therefore sought medical advice. None of these seromas were infected, pump refill could still be accomplished, and the seromas had resolved by the next refill. In one patient (H1), a seroma appeared after several years of intrathecal therapy. Nursing staff again sought medical advice, the refill was accomplished successfully, cultures of seroma fluid were negative, and the seroma resolved spontaneously.

In two patients, pumps were found to be dry at the time of refill. In patient $\mathrm{M} 4$, at the time of the first refill, the pump was dry. It was assumed that a smaller volume had been placed in the pump in the operating room than expected, but the pump was again dry at the time of the next refill. It was determined at this point, and later confirmed by long term observation, that this fixed rate Infusaid infusion pump in fact ran significantly faster $(2.2 \mathrm{ml} /$ day) than the factory stated rate of $1.17 \mathrm{ml} /$ day. Once this faster flow rate was determined, more frequent refills were scheduled, and the pump has performed flawlessly ever since. As this patient's pump ran dry very early in the course of intrathecal therapy, no significant withdrawal symptoms were observed, aside from some degree of increasing spasticity. Patient M6 with a Medtronic pump abruptly developed increasingly severe spasms in arms and legs and perhaps mild confusion two months after onset of intrathecal therapy. She was hospitalized, and the pump was found to contain only $1 \mathrm{cc}$ of medication solution upon refill. The pump was refilled and the patient responded quickly to baclofen boluses administered by the Medtronic pump and was discharged the next day with good control of spasticity on the same pump flow rate as programmed previously. The pump computer had read the pump as empty, and it was assumed that the flow rate had slowed with resulting intrathecal baclofen withdrawal. Two patients experienced significant respiratory distress while undergoing IB therapy. One of these, patient $M 4$, developed laryngospasm five hours after a 100 microgram dose of IB had been given through a temporary catheter during the initial IB testing period. This patient had a history of previous attacks of laryngospasm, and had significant dysphagia and dysarthria secondary to her multiple sclerosis so that she had been eating blended foods only. She had extreme spasticity with back spasms that would cause her to slide out of her chair so that she had to wear a seatbelt in her wheelchair at all times. It was felt the laryngospasm was not related to IB injection, and she has now successfully undergone over two years of intrathecal baclofen therapy. Patient M3, a patient with severe multiple sclerosis with complete leg paralysis and marked impairment of arm function, developed increasing complaints of shortness of breath while her oral baclofen was tapered after pump implantation. Her IB dosage had been gradually increased to gain improved control of her spasticity. The cause of this patient's dyspnea was never determined. Her vital capacity had not changed significantly from before pump implantation. Tensilon testing was negative, as was pulmonary angiography. Reducing her intrathecal baclofen dose did seem to improve her dyspnea, but over the ensuing months her baclofen dosage was again increased, with better control of spasticity, but without recurrence of her dyspnea until much higher doses were reached.

\section{Discussion}

The remarkable ability of intrathecal baclofen to reduce spasticity in patients with multiple sclerosis and spinal cord injury has been demonstrated, ${ }^{1-13}$ and is confirmed by our results. In most patients, complete flaccidity could be achieved if dose limiting side effects did not occur. In patient $\mathrm{S} 1$, sedation and difficulty with bladder emptying (the patient voided spontaneously) limited the dose that could be used, while in patient M3 with severe quadriplegia from MS respiratory muscle weakness with dyspnea was a limiting factor. Nevertheless, even in these patients very significant therapeutic gain could be made despite dosage limitations.

Baclofen is a gamma-aminobutyric acid $(\mathrm{GABA})_{\mathrm{B}}$ receptor agonist. In the spinal cord, these receptors have their greatest density in the substantia gelatinosa (Lamina II). ${ }^{14}$ They are also present at the synapse between the la afferent fibre and the spinal motoneurons, and at the synapse between some descending fibres and spinal motoneurons. ${ }^{15}$ There is good evidence from animal studies that baclofen acts on $\mathrm{GABA}_{\mathrm{B}}$ receptors on the presynaptic nerve terminals of Ia afferent fibres to reduce the 
probability of transmitter release without changing the size of the action potential in the presynaptic nerve terminal. ${ }^{15.16}$ There is however also some evidence in humans that IB may inhibit the spinal $\mathrm{H}$ reflex through post-synaptic mechanisms, ${ }^{17}$

Alternatives to IB for treatment of spasticity include oral baclofen, but for patients with severe spasticity, sufficient spinal cord levels to control spasticity frequently cannot be achieved without intolerable brain-related side effects. In contrast, lumbar intrathecal drug administration allows the achievement of high drug concentrations at the lower spinal level, with a rapid fall off of drug concentrations more rostrally. ${ }^{18}$ When baclofen is administered in this way, the cisternal CSF drug concentration is only $24 \%$ as high as in the lumbar CSF. ${ }^{19}$ Intrathecal morphine has also been used for treatment of severe spasticity, ${ }^{20}$ but has been generally replaced by the more effective IB. One of our patients (M2), received intrathecal morphine for several years with some benefit prior to initiation of IB therapy, but IB proved much superior. Surgical options for the treatment of severe spasticity include dorsal longitudinal myelotomy ${ }^{21}$ and selective functional posterior rhizotomy. ${ }^{22}$ Both require extensive laminectomies, and many patients with some residual lower spinal cord function flatly refuse destructive neurosurgical procedures. This was the case for all our study patients. Oral benzodiazepines and dantrolene are also used, but in patients with severe spasticity will often cause intolerable side effects without adequate relief of spasticity.

Our clinical results are comparable to other series. A large recent series by Coffey et al. ${ }^{10}$ concluded that IB is a safe and effective treatment for intractable spasticity. Their complications were similar to our series, except that in their larger series some infections, some skin problems over the pump site, and some mechanical pump failures occurred.

An important question is how much the improved control of spasticity contributed to the overall well-being of the patient both in terms of comfort and improved function, and at what cost both medically and economically this improvement was obtained.

Our nursing assessment and patient satisfaction surveys indicated that significant gains were made by most patients in at least several areas. Especially improved were the patient's ability to transfer or be transferred safely to and from their wheelchair, and the ability to seat the patient adequately in a wheelchair so that a patient could go about his or her business without threat to skin and without danger of being hurled from the chair by spasms. However, many other areas were significantly impacted as well, ranging from pain control and sleeping ability to improved personal hygienic care. Patients with severe spasms who were limited to bed bath previously, or required four attendants to transfer them to a bathtub could after IB therapy be easily and safely bathed by one attendant using a mechanical lift if necessary. Dressing likewise could be done much more easily and safely. As patients came off massive doses of oral baclofen and other drugs, mental status often improved dramatically, and some multiple sclerosis patients who had been known for several years as rather dull and morose became witty and vivacious.

These documented improvements were substantiated by an analysis of patient place of residence. Whereas prior to IB therapy only three patients lived in the community, and none of the rest appeared to have any prospect of leaving institutional life, after one year after initiation of IB therapy, five lived at home and one more was able to move into a group home. With longer follow-up, all but one of the nine patients was able to leave institutional care.

At what costs were these gains made? For the patients, there is no question that they are at risk for serious complications. Consistent with the literature, infections were not a major problem, although the potential is always there. Contamination of implanted pumps through contaminated drug solutions has been reported." In contrast with some earlier reports with earlicr pump models, " the pumps available now and used in our study appear to perform almost flawlessly. Our one exception was an Infusaid pump which, although it functioned well, ran at almost twice its factory specified flow rate.

Drug withdrawal due to sudden interruption of intrathecal drug delivery can be a significant problem. Abrupt withdrawal of IB can lead to increased spasticity, disorientation and seizures. ${ }^{23}$ One of our multiple sclerosis patients (M6) did develop very significant symptoms when her pump ran dry, with confusion and severe muscle spasms. Although not considered life threatening in her case, such symptoms could likely become life threatening if severe spasms occurred in a more fragile patient with limited respiratory reserve, or if seizures develop. If personnel to refill the pump or investigate the patient for possible catheter rupture are not immediately available, providing that intrathecal baclofen solution is available in the hospital pharmacy, a bolus injection of baclofen given by lumbar puncture should be considered to control serious withdrawal symptoms for several hours until the appropriate personnel can be mobilized. The surgical procedures required were not extensive, and for most patients could be easily performed under local anesthetic. In our experience, the drug delivery catheter has proved to be the most unreliable part of the therapeutic system, and this is consistent with the observations of others. In one of the largest published patient series, ${ }^{10} 22$ catheter malfunctions occurred in 18 patients out of a total patient series of 75 patients with a mean of 19 months follow-up. Catheter rupture is also the main unpredictable factor which puts patient at risk for sudden drug withdrawal. Development of more reliable catheter systems is urgently needed.

If catheter rupture is suspected, confirmation is helpful prior to surgical exploration. For this purpose we have utilized injection of Omnipaque 240 radiopaque contrast medium through the pump sideport to outline the catheter. Catheter ruptures are evident as dye extravasation from the catheter at the site of breakage, and good entry of dye into the intrathecal space confirms the catheter system is intact. A major concern with this technique is that if the catheter system is intact, a large dose of baclofen can be flushed into the intrathecal space. If the catheter is filled with concentrated solution, this could result in a significant overdose. Withdrawal of 1-2 $\mathrm{ml}$ of CSF from the pump sideport prior to injection of dye should clear the catheter of drug, and prevent inadvertent overdose. If however, CSF cannot be withdrawn through the catheter, a baclofen overdose through flushing of the catheter remains a possibility, and the patient requires careful observation after the procedure. Finally, if the catheter has been emptied of drug and then flushed, and proves to be intact, it will take some time depending upon the pump flow rate for drug from the pump to again enter the CSF space, so drug withdrawal could occur. This can be addressed by refilling the 
catheter with fluid containing baclofen through the pump sideport after the procedure, and the initial fluid withdrawn from the sideport prior to catheter flushing could be used for this purpose. Alternatively, if the patient has a Medtronic pump, fluid boluses could be delivered by the pump to refill the catheter quickly with drug containing fluid from the pump reservoir but for this the volume of the catheter needs to be known, and careful observation of the patient is important.

In two of our patients, S2 and M3, dyspnea was the major dose limiting factor in determining the maximal intrathecal drug dose tolerated. Such observations raise concern about the adequacy of coughing and predisposition to pulmonary infections. These concerns may have become a reality only in our most severely disabled patient, Ml, who also had other factors predisposing to chest infection. A respirologist interested in neuromuscular diseases would be a useful addition to any IB program which deals with markedly disabled patients.

There are several additional patient concerns. Several of our patients developed some degree of back discomfort and scoliosis secondary to relaxation of paraspinal muscles. This could be successfully dealt with by adjusting the patient's seating and adding lateral supports to the wheelchair. Our spinal injured patients however preferred to put up with their symptoms and continued to use a light-weight low-backed wheelchair.

Although IB has been reported to improve bladder function, ${ }^{24,25}$ and an occasional patient of ours (M2), reported improved bladder emptying, it was more common for our patients to complain of poor bladder emptying. In one of our patients, M6, this necessitated the introduction of intermittent catheterization. Further impairment of bladder emptying in these patients may predispose to more frequent urinary tract infections, and the introduction of intermittent catheterization can be difficult if patients do not have sufficient hand function to perform intermittent catheterization themselves. Improvement in voluntary muscle activation has been reported after IB therapy, ${ }^{26}$ but we did not see clinically significant improvement in upper limb function in our patients. In patient M5, who had marked spasticity of the upper limbs, some improvement may have been observed at high drug doses, but these could not be maintained because of sedation. In this patient, upper limb function was therefore not improved long term, but lower limb spasticity remained under excellent control at well tolerated baclofen doses. Our economic analysis of IB very much supported the use of IB therapy in well selected patients as outlined in the results section. The ability to move patients from institutions back to the community emphasizes this point. The prevention of decubitus ulcers because the patients could now be seated properly, and the ability of IB therapy to decrease the level of help the patients needed for self care were important factors. For patients $\mathrm{S} 1$ and S2, the ability to drive independently and safely allowed them much more independence, and was very helpful in facilitating their further education. According to our analysis, the cost savings in the first year of IB therapy due to less hospitalization more than pays for the pumps and the other costs of the IB program. After an average follow-up of 27 months, these benefits still appear to be maintained. Our experience with patient Ml however, would suggest that treatment of patients with multiple sclerosis with dementia and severe disability unrelated to limb weakness and spasticity may be less cost effective. The occurrence of major complications such as sepsis could also strongly reduce cost effectiveness, so that the cost effectiveness of the program rests on careful patient selection and the ability of the program to prevent or avoid major complications. For success, IB programs need to develop expertise in a number of areas. The first is patient selection. As this is a long term treatment program which depends on patient cooperation, the need to exclude patients who are uncooperative, abuse drugs or have major psychiatric problems is obvious. For our patients with spinal injury, the elimination of severe involuntary muscle spasms has been the major factor in making these patients more functional by allowing safe self-transfers and safe driving. For our multiple sclerosis patients, our most successful results have occurred in patients who, prior to therapy, could not be seated because of spasticity, who suffered skin breakdown as a result of spasticity and seating difficulty, who had marked pain with their spasms, but who maintained good mental function and had relatively minor disability related to central nervous system structures above the neck.

Our program included only one head injured patient who was entered into the program because his rehabilitation was at a complete standstill 27 months after head injury because of spasticity. Once IB therapy was started, this patient's physiotherapy and rehabilitation program progressed rapidly, the patient eventually became ambulatory with assistance after many months, and no longer required hospitalization. Functional recovery was limited however by very significant dementia. It is difficult to draw conclusions on the basis of one patient, but in patients with head injury and significant intellectual loss, IB therapy should probably be used cautiously, and indications need to be developed. It is of interest that our head injured patient was the only patient in whom the intrathecal baclofen was eventually tapered after over three years of therapy, and pump removal is now being considered.

With regard to program organization, we have several observations. Firstly, dedicated and trained nursing personnel can very successfully perform the pump refills with a minimum of physician supervision, provided that drug orders are discussed and potential problems are reported to the physician team immediately. Secondly, it is mandatory to have strong rehabilitation input into an IB program. As an example, seating requirements change quickly as IB therapy is started, and major changes in patient equipment are required. Thirdly, neurological and neurosurgical backup must be available, as these severely disabled patients can develop medical problems, IB therapy related or otherwise, any time day or night. Especially problematic here is the problem of catheter rupture. For these non-ambulatory patients, the non-programmable pump such as the Infusaid pump is often sufficient, as frequent changes in dosage are not necessary, and these pumps offer the possibility of many years of service without requiring replacement. While the programmable Medtronic pump does require replacement approximately every five years because of battery rundown, this pump offers much greater flexibility in terms of rapid dosage adjustment using telemetry through the abdominal wall. Also, with the use of concentrated baclofen solution, the pump can be run very slowly, so that refills are required less frequently, even as infrequently as every three months if the patient's dosage requirements are not high. Because dosage adjustments can be made easily, even in the immediate post-operative period, the patient's dosage can be titrated rapidly to symptoms, and earlier hospital 
discharge may be possible. The non-programmable pump in contrast requires a pump refill with change in drug concentration if the dosage needs alteration, as the pump flow rate is fixed. This can be a problem, especially in the early post-operative period.

In conclusion, IB can improve patient quality of life, and can be a cost effective therapy. Careful patient selection is essential, and the drug catheter is that part of the system most vulnerable to failure. Because of the potential for complications, initiation of IB programs should not be undertaken lightly, and for a successful program it is mandatory that a well organized multi-disciplinary team be in place.

Note added in Proof: Since submission of our manuscript, another cost analysis of patients treated with intrathecal baclofen has been published (P Nance et al. Can J Neurol Sci 1995; 22: 22-29). These authors found a savings per patient of approximately $\$ 16,000$ per year as a result of reduced hospital in-patient days in the two years post-pump implantation compared to the two years pre-implantation. These savings then would again more than cover the costs of the infusion pumps which are not included in these figures.

\section{ACKNOWLEDGEMENT}

This work was supported in part by the Calgary General Hospital, Research and Development Committee.

\section{REFERENCES}

1. Penn RD, Kroin JS. Continuous intrathecal baclofen for severe spasticity. Lancet $1985 ;$ 125-127.

2. Penn RD, Kroin JS. Long-term intrathecal baclofen infusion for treatment of spasticity. J Neurosurg 1987; 66: 181-185.

3. Penn RD, Savoy SM, Crocos D, et al. Intrathecal baclofen for severe spinal spasticity. N Engl J Med 1989; 320: 1517-1521.

4. Zierski J, Muller H, Draile D, Wurdinger T. Implanted pump systems for treatment of spasticity. Acta Neurochir 1988; Suppl 13: 94-99.

5. Ochs G, Struppler A, Meyerson BA, et al. Intrathecal baclofen for long-term treatment of spasticity: a multi-centre study. J Neurol Neurosurg Psychiatr 1989; 52: 933-939.

6. Loubser PG, Narayan RK, Sandin KJ, Donovan WH, Russell KD. Continuous infusion of intrathecal baclofen: long-term effects on spasticity inspinal cord injury. Paraplegia 1991; 29: 48-64.

7. Broseta J, Garcia-March G, Sanchez-Ledesma J, Anaya J, Silva I. Chronic intrathecal baclofen administration in severe spasticity. Stereotact Funct Neurosurg 1990; 54+55: 147-153.

8. Lazorthes Y, Sallerin-Caute B, Verdie J-C, Bastide R, Carillo J-P. Chronic intrathecal baclofen administration for control of severe spasticity. J Neurosurg 1990; 72: 393-402.

9. Meythaler JM, Steers WD, Tuel SM, Cross LL, Haworth CS. Continuous intrathecal baclofen in spinal cord spasticity: a prospective study. Am J Phys Med Rehabil 1992; 71: 321-327.
10. Coffey RJ, Cahil D, Steers W, et al. Intrathecal baclofen for intractable spasticity of spinal origin: results of a long-term multicentre study. J Neurosurg 1993; 78: 226-232.

11. Penn RD. Intrathecal baclofen for spasticity of spinal origin: seven years of experience. J Neurosurg 1992; 77: 236-240.

12. Albright AL, Cervi A, Singletary J. Intrathecal baclofen for spasticity in cerebral palsy. JAMA 1991; 265: 1418-1422.

13. Braunsdorf WE, Kuhlendahl HD, Volkheimer A, Behrens C, Kleiter K. Continuous intrathecal baclofen therapy using an implantable pump system insevere spasticity. Neurochirurgia 1990; 33: 16-19.

14. Kroin JS, Bianchi GD, Penn RD. Intrathecal baclofen down-regulates $\mathrm{GABA}_{\mathrm{B}}$ receptors in the rat substantia gelatinosa. J Neurosurg 1993; 79: 544-549.

15. Edwards FR, Harrison PJ, Jack JJB, Kullman DM. Reduction by baclofen of monosynaptic EPSPs in lumbosacral motoneurones of the anesthetized cat. J Physiol 1989; 416: 539-556.

16. Peng Y-y, Frank E. Activation of $\mathrm{GABA}_{B}$ receptors causes presynaptic inhibition at synapses between muscle spindle afferents and motoneurons in the spinal cord of bullfrogs. J Neurosci 1989; 9: 1502-1515.

17. Azouvi P, Roby-Brami A, Biraben A, et al. Effect of intrathecal baclofen on the monosynaptic reflex in humans: evidence for a postsynaptic action. J Neurol Neurosurg Psychiatr 1993; 56: 515-519.

18. Kroin JS, Ali A, York M, Penn RD. The distribution of medication along the spinal canal after chronic intrathecal administration. Neurosurgery 1993; 33: 226-230.

19. Kroin JS, Penn RD. Cerebrospinal fluid pharmacokinetics of lumbar intrathecal baclofen. In: Lakke JPWF, Delhaas EM, Rutgers AWF, eds. Parenteral Drug Therapy in Spasticity and Parkinson's Disease. Carnforth, UK, Parthenon Publishing, 1991: 73-83.

20. Erickson DL, Blacklock JB, Michaelson M, Sperling KB, Lo JN. Control of spasticity by implantable continuous flow morphine pump. Neurosurgery 1985; 16: 215-217.

21. Putty TK, Shapiro SA. Efficacy of dorsal longitudinal myelotomy in treating spinal spasticity: a review of 20 cases. J Neurosurg $1991 ; 75 ; 397-401$.

22. Steinbok P, Reiner A, Beauchamp RD, et al. Selective functional posterior phizotomy for treatment of spastic cerebral palsy in children. Ped Neurosurg 1992; 18: 34-42.

23. Siegfried RN, Jacobson L, Chabal C. Development of an acute withdrawal syndrome following the cessation of intrathecal baclofen in a patient with spasticity. Anesthesiology 1992; 77: 1048-1050.

24. Nanninga JB, Frost F, Penn R. Effect of intrathecal baclofen on bladder and sphincter function. J Urol 1989; 142: 101-105.

25. Frost F, Nanninga J, Penn R, Savoy S, Wu Y. Intrathecal baclofen infusion: effect on bladder management programs in patients with myelopathy. Am J Phys Med Rehab 1989; 68: 112-115.

26. Latash ML, Penn RD, Corcos DM, Gottlier GL. Effects of intrathecal baclofen on voluntary motor control in spastic paresis. J Neurosurg 1990; 72: 388-392. 